\title{
Research Paper: Sustainability Analysis of Rural Settlements in the Western Region of Lake Urmia
}

Ali Nasiri

1. Assistant Professor, Payam Noor University, Iran.

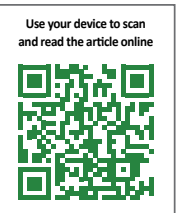

Citation: Nasiri, A. (2020). Sustainability Analysis of Rural Settlements in the Western Region of Lake Urmia. Journal of Sustainable Rural Development, 4(2), 277-288. https://doi.org/10.32598/JSRD.4.2.13

doit: : https://doi.org/10.32598/JSRD.4.2.13

Article info:

Received: 20 April 2019

Accepted: 17 Oct. 2020

\section{Keywords:}

Rural Settlements, Spatial Analysis, Morphotectonic Stability, ISO Data, Fuzzy

\begin{abstract}
A B STRACT
Purpose: Today, human-natural environment interactions in different spatio-temporal dimensions have become more widespread and increasingly complex. This has caused environmental instability with more frequency and intensity than ever before to become a serious environmental issue for settlers and planners. Risks of environmental instability include various types of natural environment instability, floods, earthquakes and various epidemics such as influenza, corona, etc. Especially in our country, which is located in new geological and mountainous lands, one of the main problems of settlements is morphotectonic instabilities. Therefore, it clarifies the necessity of morphotectonic stability analysis as a sustainability tool for land use determination. The instability of settlements in the research area has not been studied or reported.
\end{abstract}

Methods: For analysis and determination of morphotectonically stable zones of the research area, various multivariate spatial analysis methods such as fuzzy and ISO Data as well as geomorphic indices such as W, $\mathrm{SL}, \mathrm{Hi}, \mathrm{Ar}$ and SMF were used. The Iat index was used to evaluate the relative stability of morphotectonic zones. Relevant data such as altitude and slope, recorded earthquake data, faults and geological and geomorphological data were used in the present study. Based on elevation systems, morphostructural and tectonic systems, fault systems (with various network patterns, different nodes and fracture trend and length) as well as geostructural and seismic systems, morphotectonic zones of the region were identified and determined.

Results: The results of this study show that in the study area, there is a Horst and Graben system with an east-west trend, which is formed by a system of faults parallel to the north-south trend. 4 different morphotectonic patterns (A, B, C, D) were identified in the research area with distinctive characteristics and different coefficients of morphotechnical stability.

Conclusion: According to the results of the analysis of the Iat index, $57 \%$ of the rural settlements are located in zone $\mathrm{A}$, which is morphotectonically stable; $23.5 \%$ of the settlements are located in zone $\mathrm{C}$, which has a lot of instability; $16 \%$ of the settlements are located in zone B and $9.4 \%$ are located in zone $\mathrm{D}$, which show more severe and severe morphotectonic instability with different coefficients, respectively. The results show that the main cause of environmental instability in the western region of Lake Urmia is the fault system activity.

\section{* Corresponding Author:}

Ali Nasiri, PhD

Address: Payam Noor University, Iran.

Tel: +98 (914) 1866653

E-mail:pnuiran@yahoo.com 


\section{Introduction}

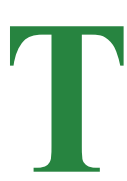

ypes of indicators of environmental instability in rural settlements are divided into four general categories: economic, social, political and natural. Indices of instability of natural origin include morphotectonics and geology (such as earthquakes, faults, drifts, creeps, and landslides), climates (such as storms, floods, droughts, and heat and cold waves) and biological (plant and animal pests and epidemics). The nature and origin of environmental instability in rural settlements in the study area is mainly morphotectonic. Therefore, considering this issue (active status and its morphotectonic nature on the one hand and the existence of many rural settlements in it) is one of the main reasons for choosing the subject and region for the present study. The location of the study area in the active tectonic zone and the existence of active fault systems such as Mako-Urmia, Bari, Nazlu, Shahrchai and Baranduz in it cause active tectonic movements in the area. On the other hand, morphotectonic conditions (uplift and depression), soil type (clay and silt), geological structure and coordination of slope layers with topographic slope and topographic status (high altitude and slope) have caused instability in the region. These factors have caused environmental instability due to landslides, liquefaction, erosion and subsidence. These factors have challenged the sustainability of rural settlements in the region. For reasons such as fertile land and plenty of water in the area, there are many rural settlements that have large populations. Their morphotectonic stability status is unknown. This type of study has not been conducted or reported in the area. Therefore, the present study is critical to identify morphotectonic units and evaluate their instability for future stabilization planning of rural settlements in the region. Accordingly, the purpose of this study is to analyze the morphotectonic stability of the region in order to determine the instability of rural settlements for future development plans. The following are the research questions: What is the environmental sustainability of rural settlements according to the morphotectonic variables of the region? What data and methods can be used to determine and analyze the environmental sustainability of rural settlements? What factors affect the environmental instability of rural settlements in the region? Multivariate spatial analysis techniques, spatial data and morphotectonic indices were used to answer these questions.

The western region of Lake Urmia is the study area. This area mainly includes the city of Urmia in the province of West Azerbaijan and the center of that province. It is bounded by Salmas city from the north, Urmia Lake from the east, Nagadeh and Oshnaviyeh cities from the south and Turkey from the west (Figure 1). The study area has an area of 185.5 square kilometers, which is mainly covered by the city of Urmia. Urmia city has 5 districts, 20 village districts and 614 villages based on national divisions in 2000 .

The tectonic position of the study area is bounded on the east by the Mako-Zarrineh fault (graben of Lake Urmia). It connects to the mountains of the international border from the west. These mountains mainly have complex and different axes from north to south, and some of them have west-east trends and volcanic mountain cones. It leads from the north to Salmas plain and fault and from the south to the flat basin of Nagadeh plain. In this region, from west to east, in a short route, the height of the mountains decreases from 3600 meters in the west to 1050 meters on the shores of Lake Urmia. Also, as we move from west to east, the amount of rainfall decreases and in the border mountains, especially around Sardasht, the amount of rainfall reaches $800 \mathrm{~mm}$, but in Lake Urmia, it decreases to less than $300 \mathrm{~mm}$.

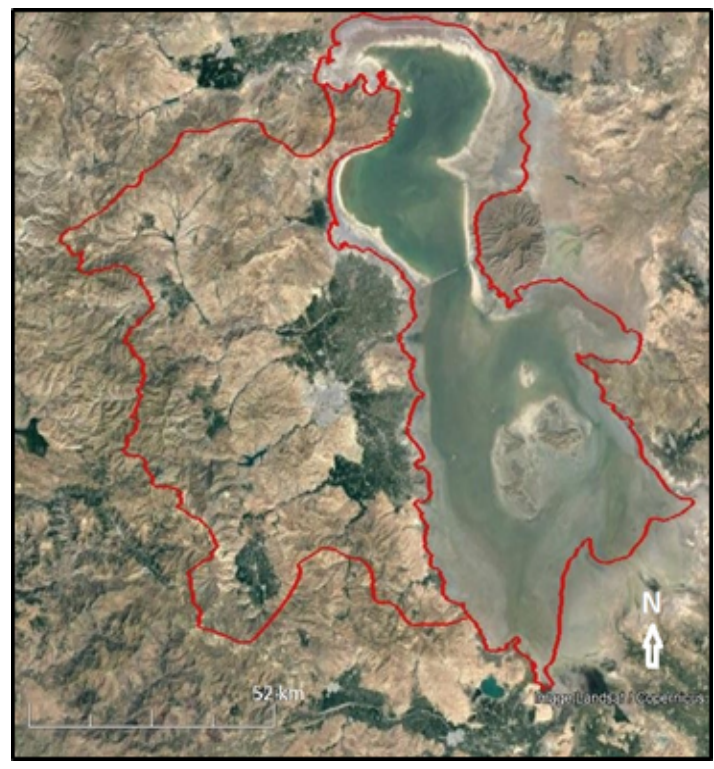

Figure 1. Location of the study area (Source: Google Earth) 


\section{Literature Review}

Many studies on morphometry and morphotectonics have been conducted in the world, but no research on the analysis of morphotectonic stability of rural settlements was found in foreign sources. Morphotectonic studies to identify and determine morphotectonic units with different factors, criteria and landscapes began with the first demarcation of macro geomorphological units. Iran is part of the Alpine-Himalayan tectonic zone, located between the Eurasian blocks in the north, the African and Saudi blocks in the south, and the Indian and Australian blocks in the east. Iran's position is a region under pressure from these blocks, especially the Arab and Eurasian plates. At present, these plates are moving towards each other at a speed of about $24 \mathrm{~mm}$ per year. Geomorphological and morphotectonic formations of Iran are under the control of this compressive environment. This convergence towards the Mediterranean continues. The intensity of convergence in the eastern Mediterranean is more severe than in the western Mediterranean in terms of the impact of the subduction zone on the central Mediterranean and the collision zones of Turkey (eastern Mediterranean) and western Spain (Rodriguez \& Barba, 2004: 755). The study of neotectonic movements is based on structural decomposition indices. Guerasimov (1964) provided these indicators. Researchers such as Gorielov et al. (1973), Guerasimov (1973) and Rantsman (1973) Guerasimov, Mescheriakov (1966) and Rantsman (1961, 1979) modified and developed these indicators. Morphotectonic analysis based on the theoretical foundations of tectonics, structure and morphostructure is included. These analyses are based on the genetic principle of origin and development of geomorphological building units, where unevenness is the result of the interaction of internal and external processes. According to Alexiskaya et al. (1977), formation maps can be the starting point for studying many geophysical problems. Severe earthquakes are associated with fault network nodes (Zhidkov et al., 1975). Morphotectonic structures are formed near the intersection of the largest fault line systems. The physical mechanism of fault node formation was first proposed by Mackenzie and Morgan in 1968, but Gabrielov et al. (1996) discuss the concentration of severe earthquakes in such structures. However, some researchers emphasize that structural zoning should be done without considering and using seismic data (Rodriguez \& Barba, 2004). Earthquakes and tectonics are the results of the same internal processes of the upper mantle and the earth's crust because earthquakes occur in different geological units, which in turn cause a variety of different environmental instabil- ity conditions. The use of geological data in the assessment of instability and seismic hazards shows that earthquakes are a continuation and result of the process of the last tectonic stage, the effects and evidence of which are preserved by various events in rocks and structures. Mathew (2016) emphasized tectonic control and climatic forcing on transient channel incision and erosion in North Borneo.

In Iran, studies on determining the morphotectonic stability of rural settlements have not been reported. From a morphotectonic point of view, this study has, for the first time, studied the effects of morphoneotectonics on the environmental sustainability of rural settlements. Mahdavi et al. (2004) studied the role of natural geographical factors in instability and rural migration in Zanjan province. They showed that environmental factors and capabilities such as topography, slope, temperature and rainfall and land capability have a significant impact on the volume of migration and emptying of Zanjan villages. Soleimani et al. (2015) studied the factors affecting the instability of rural settlements in Iran and found that these factors are divided into national and transnational categories. National factors include non-native theoretical foundations and development patterns in Iran, shortcomings and problems governing the planning system, government rent, educational shortcomings and low literacy, problems and shortcomings of rural management, poor facilities and services. Transnational factors include rationalism and domination of nature, the industrial revolution, population growth, and the nature of development. Annabestani and Salehi (2010) measured the stability of settlements in the alluvial fan of Dasht-e Jovien. They found that there is a significant relationship between natural data of alluvial fans (i.e. water and agricultural lands) and the trend of population changes in the statistical period 1976-2006. However, few studies have been reported on tectonic stability, which can be mentioned. Maghsoudi et al. (2016) estimated the range of tectonic activity of the southern part of the Minab fault and its eastern fault system through morphometric data to determine the stability of the region (east of the Strait of Hormuz). In general, their results show that the amount of tectonic activity is higher in the southern edges of the anticlines and among the anticlines studied in the two indices of Saghari valleys and mountainous sinusitis, anticline number one has the highest amount of tectonic activity. Because morphotectonic studies were the background of this type of study, they are referred to here.

In Iran, several tectonic zonings have been done. Stahl's zoning (1911: quoted by Eyvazi 2000: 20) has 
divided the territory of Iran into three regions: Alborz, Zagros and Central Iran. Stocklin (1974: quoted by Darvishzadeh, 2006:110) has divided the land of Iran into 9 tectonic zones in which the research area (west of Lake Urmia) is part of the Sanandaj-Sirjan zone. Nabavi (1976: quoted by Darvishzadeh, 2006:111) has classified the area of Iran into 16 construction-sedimentary units of which the study area is part of Khoy-Mahabad region. Eftekharnejad (1980: quoted by Eyvazi 2000), according to criteria such as time, type of crust (continental or oceanic) and orogenic history, has divided the land of Iran into 13 regions, of which the research region is part of the Hamedan-Urmia region (Eivazi, 1995). In another geological zoning of this region (west of Lake Urmia) including the region of Central Iran, the magmatic zone of Urmia-Dokhtar and Sanandaj-Sirjan is shown (Mohammadi et al., 2011). Aghanbati (1986), Barbarian (1981), Barbarian and King (1981), Davoodzadeh et al. (1986), Boleyn (1991), Chubert and Favormort (1980), Davoodzadeh and Defenbach (1987) and Zamani et al. (2009) geographically, based on the history of orogeny and structural patterns, the land of Iran was divided into different tectonic and sedimentary regions. Nowruzi (1976 and 1979), Taheri and Niazi (1981), Ambersis and Melville (1988) and Karakisis (1994), Qalandarzadeh et al., (2003), Eskandari et al., (2003) and Moinfar et al. Earthquakes were divided into different seismic units (quoted in 2009). These zonings are vague and associated with great uncertainty. These studies (zoning) have been done without quantitative analysis, are more subjective, and it is difficult to provide an accurate interpretation of the large geological data and accelerometer of the country. Thus, the morphotectonic stability of the region has not been studied so far, which has been investigated in this study.

\section{Methodology}

In this study, recorded seismic data (intensity, depth, density and distance from earthquake centers) from the list of Ambersis and Melville (1982) and Barbarian (1994) were used. Fault networks (fracture length, density, distance from fault lines) from the map of geological data of the region and Google Earth 2020 satellite images, geological data, topographic data (altitude, slope, geographical direction and DTM) and hydrography of National Mapping Organization, geomorphological data of Google Earth images and Earth Capability Map were used for morphotectonic analysis. Morphotectonic stability of rural settlements are controlled by a set of variables such as fault network, location of earthquakes (seismic springs), active tectonics and spatial features such as topographic data (altitude, slope and geographical direction), geomorphology and geology (structure of rock layers, rock types and their slope), soil type and hydrology. These variables determine the morphotectonic stability of the environment. Morphotectonic units are determined using the above variables. Geomorphic indices (Hi, Ar, SMF, w, SL) are calculated in each of the mentioned units. The activity status of each morphotectonic unit is evaluated by the results of calculations of the mentioned geomorphic indicators. In the next step, the stability of morphotectonic units is measured using the IAT stability index. Finally, according to the values obtained from the results of the stability index calculations, the morphotectonic stability status of rural settlements in the research area is determined based on the very active (very unstable), active (unstable) and low or inactive (stable) status.

Fault system data are important in the morphostructure analysis of any region. The density layer of fault networks is obtained by determining the number of faults per unit area (Cotilla et al., 1991). This map shows the degree or extent of crust fracture in each area. In the present study, the map was generated using the Density technique from the spatial analysis set in ArcGIS 3.10. The high degree of compliance of earthquake foci and fault lines and fractures (Figure 5a) more confidently confirms the earthquake fault hypothesis (Mogi, 1967 quoted in Cotilla et al., 2004). Morphostructural zones or units are defined based on terrestrial structures; in other words, topographic data (Chigariov 1977; Nikolaev, 1982 citing Cotilla et al., 2004). Geomorphic and tectonic maps explain the structures of the earth's crust solely on the basis of one of two geomorphic or geological pieces of evidence (Cotilla et al., 2004). In this paper, both structural and geomorphic evidence were used to explain and determine morphotectonic zones and determine their stability. Given the principle of complexity and complex spatial relationships of factors with an internal and external organization, determining what factors have a greater impact on the construction and morphotectonic stability of the region is not easy, especially if the various factors are different in nature. These conditions make data analysis more difficult and often problematic. In the above conditions, data processing requires complex algorithms with a wider range of operations and also requires complex and specific analysis. In such circumstances, quantitative spatial analysis is a powerful tool in processing such information and data with complex spatial relationships. Therefore, in this study, according to expert experiences, a suitable algorithm was implemented to solve the mentioned problems and multivariate spatial analysis was used (Figure 4). 
After preparing the recorded seismic data such as earthquake magnitude, earthquake depth, earthquake density, distance from seismic sources, slope, altitude data, Morphoisohypses index (Ar), stability status of geological units, line length, node network and kinetic faults, the relevant information layers required were prepared and extracted in SPSS (M.11), Excel and ArcGIS10.3 software during primary and intermediate processes. In the next step, using spatial analysis methods with techniques such as kriging, fuzzy and multivariate analysis of ISO data, the layers were analyzed. Finally, the morphotectonic zones of the region were determined. The stability of morphotectonic zones of the region was determined by calculating the Iat coefficient (Figure 4).

The fuzzy linear function is used to scale the values of the raster layers related to the desired variables. These layers are converted on a scale of 0 to 1 using the fuzzy linear conversion function. A value of 1 indicates full membership in the fuzzy set, and a decrease in the number of memberships to 0 indicates no membership in the fuzzy set. In this study, the minimum and maximum linear functions of fuzzy conversion according to the minimum and maximum data values were considered.

Spatial analysis of data layers was performed using Geographic Information System (GIS) technology with Isodata algorithms in ArcGIS 3.10 environment. According to the mentioned topics, a four-step algorithm for data analysis and processing was designed as follows:

A) Identification of morphotectonic effective variables in the region

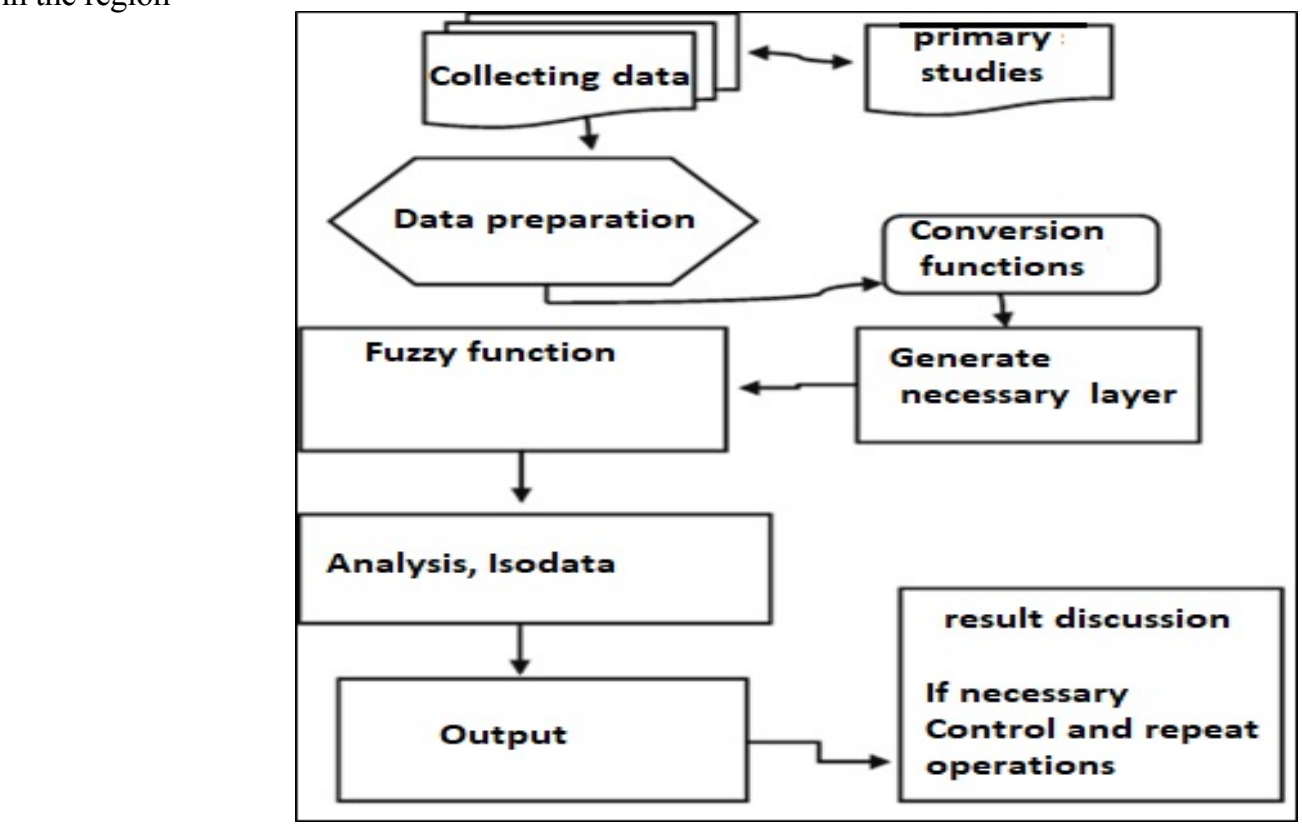

Figure 2. Research flowchart
B) Preparation of related layers and interpolation and conversion to raster

D) Standardization of data with fuzzy linear algorithm and creation of statistics file

E) Final processing and analysis of layers with Isodata algorithm

The Isodata algorithm is defined as follows:

Implementation of this method includes the following steps:

1- Selection of point $\mathrm{C}$ in multidimensional space as the primary centers of morphotectonic units, which is defined as follows. $\mu \mathrm{i}_{\mathrm{n}}, \mathrm{i}=1, \ldots, \mathrm{c}$ The choice of $\mu \mathrm{i}$ at this stage is optional. To avoid creating inappropriate clusters with unusual data, it is usually best to select primary class centers with a uniform distribution throughout the data to obtain a suitable result.

Determining the number of morphometric units with initial reviews of basic data and other available information and resources

\section{2- Determining the number of repetitions}

3- Determining the percentage of unchanged pixels in each iteration

4- Determining the amount of standard deviation of morphotectonic units 
5- The position of each pixel in multidimensional space is evaluated and this pixel belongs to the nearest morphotectonic class.

6- In determining the distance, Euclidean distance is usually used in multidimensional space.

7- The new mean for each of the morphotectonic units calculated is shown by the following symbol:

$$
\mu \mathrm{i}_{\mathrm{n}}, \mathrm{i}=1, \ldots, \mathrm{c}
$$

Where $\mathrm{n}$ represents the $\mathrm{nth}$ mean calculated for unit $\mathrm{i}$.

8- If $\left|\mu_{l(n)}-\mu_{i(n-1)}\right| \leq \sigma$ clustering ends, otherwise return to step 6 and clustering is repeated.

SSE, the sum of error squares is one of the criteria for measuring the quality of data analysis and classification, which is calculated as follows (Equation 1):

$$
S S E=\sum_{c_{t}} \sum_{x c_{t}}\left(x-\mu_{i}\right)^{t}\left(x-\mu_{i}\right)=\sum_{c_{t}} \sum_{x c_{i}}\left\|x-\mu_{i}\right\|^{2}
$$

This index shows the set distance of the pixels from the center of the corresponding clusters. If the distances of $\mathrm{X}$ from the centers of the clusters are small, the amount of SSE will be less and the determination of the clusters will be of the desired quality (lowest SSE). After clustering, morphotectonic zones can be examined and the following modification operations can be performed on them.

Any cluster that has a very low frequency and consists of several pixels often has less information value, and these clusters can be removed using post-processing techniques or merged into a large adjacent area.

Some clusters are so close together that their separation is actually illogical or they are combined according to the principle of geography (spatial correlation or proximity-similarity). Another issue that is interesting in the Isodata algorithm is the separation of large clusters into two or more new clusters.

The method of clustering moving averages requires prior determination of the expected number of classes (or clusters) along with their location. In practice, the actual or optimal number of classes is unknown, and therefore more classes are selected. In the present study at this stage, the number of classes was determined based on data reviews, aerial photographs and satellite images and identification of morphotectonic patterns. The resulting inseparable clusters can be merged or integrated after processing and analysis. The possibility of automatic determination of clusters is one of the advantages of this method because the averages in the repetition steps are changed to reduce the amount of error and thus the clusters (with the least amount of error) find the optimal position.

\section{Findings}

As mentioned in the introduction, environmental data determine the type of sustainability of rural settlements in that environment. In other words, the nature of sustainability depends on their environmental origin. Our country and especially the research region was formed in the new geological periods (Cenozoic), i.e. Alpine-Himalayan orogeny, and is considered a young land. Currently, tectonic activities are not over and they are still going on in various forms. In young geological lands, the most common type of instability of rural settlements is tectonic instability. In mountainous lands, topographic factors along with active morphotectonic factors intensify environmental instabilities. The most common type of environmental instability in these lands is morphotectonic instability. Therefore, here we consider the morphotectonic findings of rural settlements.

Topographic maps are very useful tools in the application of geomorphological methods for quantitative and qualitative analysis of Morphostructure (Filosofov, 1960). Topographic maps are the basic data for producing a special set of maps called morphoisohypses (Jain 1980). These maps generalize the form of the land's primary origin by taking into account baselines of the mountains or the height of the roughness in each area.

The early stages of neotectonic studies are the arrangement and classification of mountain elements (Gonzales et al. 1989). Cotilla et al. (1991), in Cuba, found a direct link between the morphoisohypses map and the base map for large structures. The maximum height index (Ar) in each region is the maximum height difference per unit area (Cotilla et al. 1991). This parameter makes it possible to identify erosion zones with different erosion and instability rates. High values of the Ar index indicate highly deformed tectonic zones. The spatial variability of the Ar index makes it possible to identify tectonic instability and uplift zones (i.e. active tectonic zones) relative to adjacent zones (Cotilla et al., 1997:756). Of course, many indicators for morphotectonic analysis as well as tectonic deformation of landforms have been proposed and used by researchers, which are called geomorphic indicators such as hypsometric integral (Hi), slope index of main canal length (Sl), symmetry of basin hydrographic 
network. (Af), the ratio of the width of the valley floor to its height (Vf), the symmetry index (cross) of the basin topography $(\mathrm{T})$, the shape of the basin hydrographic network (Bs), the ratio of the maximum width of the basin to the outlet width (W) (Bahrami, 2012: 37) and Index of active tectonic relativity (IAT). No specific indicators have been defined for morphotectonic instability studies. Geomorphic indices can be used to analyze the instability of morphotectonic zones.

In this paper, for the first time, the Ar index was used to produce a morphoisohypses map of the region (Figure 4b). To produce the morphoisohypses layer of the region, the Ar index was used by spatial analysis of the DTM layer using Equation 1. Digital model of ground elevation, slope and direction was obtained by using the Kriging model from digital topographic maps of the region at a scale of 1: 50,000 and satellite images. In addition to the mentioned indices, morphoisohypsometric index was used to identify and determine morphotectonic instability. This index identifies areas with severe morphotectonic activity and extreme elevation changes. As mentioned, the morphoisohypsometric map was generated using the Focal statistics spatial analysis technique with the definition of $3 * 3$ Window statistic which calculates the difference between the highest height and the lowest in the window and puts it in the center pixel (Figure 4 a). Values for each pixel in the output are determined by examining pixel by pixel from Equation (2) below.

Focal range $=$ focal maximum - focal minimum

Fault density layers, length of fault lines, distance from fracture lines as well as seismic epicenter layers were prepared based on recorded data. Then the layers of earthquake density, earthquake intensity, depth of earthquakes and distance from the epicenters of earthquakes were generated using the Kriging method from that data. The hydrographic network layer and its ranking as well as the geological layer were produced for use in the next processing. The fuzzy method was used to scale the data of the respective layers, thus all the data of the mentioned layer were standardized in the range between 0 and 1 (Figure $3 b$ ). Then, the final analysis was performed on the relevant layers using the Isodata model based on spatial correlation, and the final results were obtained.

\section{Relative evaluation of morphotectonic activity (IAT)}

The relative evaluation of morphotectonic activities is obtained from the following relation:

$$
\text { Iat }=\mathrm{S} / \mathrm{N}
$$

Iat - relative activity index, $\mathrm{S}$ - the sum of classes of calculated geomorphic indices and $\mathrm{N}$ - number of calculated indices. The different classes of the index are as follows (Hamdoni et al. 2008 quoted by Karami 1388):

Intense morphotectonic activity: $1.5>$ Iat $>1$, high morphotectonic activity: $2>$ Iat $>1.5$, moderate morphotectonic activity: $2.5>$ Iat $>2$ and low morphotectonic activity: $2.5<$ Iat. To evaluate the stability of morphotectonic zones of rural settlements in the study area, the following 5 geomorphological indicators have been used and the results are listed in Table 1.

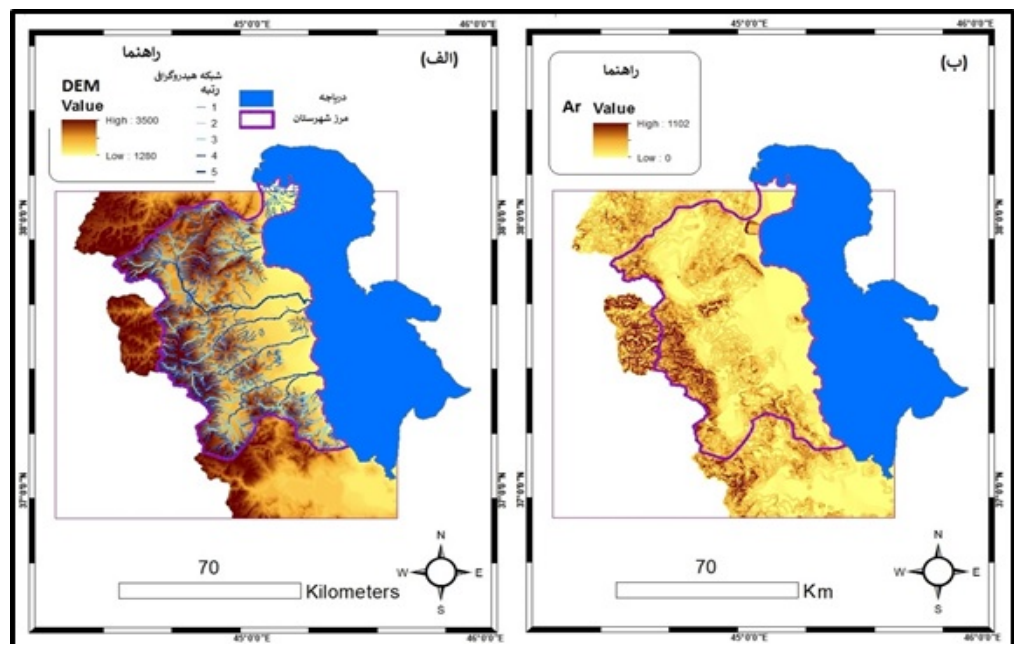

Figure 3. Digital elevation layer of the earth and the hydrographic network (a) and the morphoisohypses layer of the Ar index (b) 


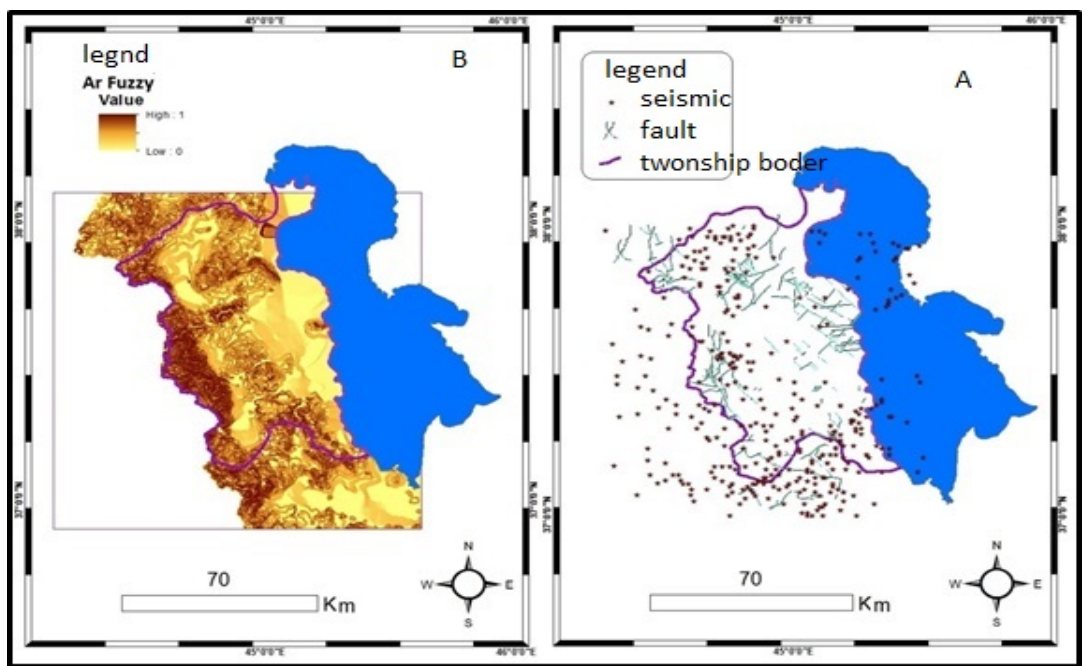

Figure 4. Layer of faults and earthquakes (A) and fuzzy layer of morphoisohypses (B)

Table 1. Geomorphic indices of morphotectonic zones of rural settlements study area

\begin{tabular}{rrrccccc}
\hline zone & & index & W & SL & HI & AR & SMF \\
\hline & A & 1.92 & 146 & 0.25 & 13 & 1.31 \\
& B & 15 & 508 & 0.56 & 42 & 1.16 \\
& C & 11.7 & 260 & 0.33 & 73 & 1.35 \\
& D & 11.35 & 1638 & 0.52 & 44 & 1.26 \\
\hline
\end{tabular}

Table 2. Sustainability assessment of morphotectonic zones of rural settlements of the region based on IAT index

\begin{tabular}{|c|c|c|c|c|c|c|c|c|}
\hline $\begin{array}{l}\text { Index } \\
\text { zone }\end{array}$ & w & SL & $\mathrm{Hi}$ & $\mathrm{Ar}$ & SMF & lat & Morphotectonic activity class & Stability status \\
\hline A & 3 & 3 & 3 & 3 & 2 & 2.8 & low & Stable \\
\hline B & 2 & 1 & 1 & 2 & 1 & 1.4 & More severe & More severe instability \\
\hline C & 2 & 3 & 2 & 1 & 1 & 1.8 & moderate & High instability \\
\hline D & 1 & 1 & 1 & 2 & 1 & 1.2 & Severe & Severe instability \\
\hline
\end{tabular}

As can be seen in Table 2, according to the Iat index, morphotectonically, only zone A shows stability and zone B shows more severe instability, D shows severe instability and $\mathrm{C}$ is in moderate instability (Figures 7 to 11). This indicates that the study area is morphotectonically very active.

\section{Discussion}

Due to the tectonic position of the study area, which is located in the middle of the tectonic belt and active Alpine-Himalayan orogeny, it is the junction of the plateaus of Iran and Anatolia. This position is at the junction of tectonic units of Iran (Alborz, Zagros and Central
Iran) between volcanic massifs and large faults of Tabriz in the east and Urmia fault in the west. Thus, it has caused the formation of the graben system in the western region of Lake Urmia. The results show that this type of morphotectonic system (Fault type) prevails in the western region of the lake as Horst (highlands) and graben (plains). The landscape of its morphotectonic fault system from east to west has regularly been identified in 4 morphotectonic zones: A, B, C, and D (Figure 5). The results also show that the above four morphotectonic zones with distinct characteristics and different coefficients of morphotectonic stability exist in the study area, so they were determined (Figure 12). Thus, the zones that have relatively high Ar and Iat indices and the occurrence of 
the most earthquakes and high densities and extensive fault network and severe elevation changes and severe erosion of riverbeds, are more tectonically active. These zones show the stable morphotectonic status of rural settlements in the region (Table 2).

As shown in Table 3 and Figure 11, the highest density of $57 \%$ of rural settlements (348 villages) is located in zone A, which is morphotectonically stable. This zone consists of alluvial fans of several rivers such as Nazluchay, Rouzeh Chay, Shahrchai and Baranduz Chai, which have very fertile soil and abundant water. This zone spreads between the lake and the mountains of zone B. Zone B is located at $23.5 \%$ of rural settlements, which shows more severe instability in terms of morphotectonic variables based on the mentioned indicators. In Zone $\mathrm{C}$, the reduced density of the rural settlements is $16 \%$ of the villages located in it, which are in a state of high environmental instability. Zone $\mathrm{D}$, which forms the western mountains (border), comprises of $4.9 \%$ of the village settlements, which are morphotectonically severely unstable. The important point about the spatial distribution of rural settlements of the research area is that they were reduced from zone A, (i.e. from east to west) to zone D, so their density was reduced from $57 \%$ to $4.9 \%$. This is also clearly seen in Figure 11. Perhaps the reason is the very high environmental capacity and fertile alluvial soil and abundant water of zone A. The results of the research findings as well as the study of each variable show that faults are the most important factor in the morphotectonic instability of rural settlements in the region. The results of this study show that regional factors and systems such as morphodynamic factors and fault systems have a decisive role in geomorphotectonic and environmental instability of the region and are under the control of the intensity of convergent movements of Eurasian and Arabian plate systems. At present, according to the evidence and effects, the changes and developments of the morphotectonic structure of the region are dominated by fault systems and external dynamics (water erosion) (Figure 6).

Table 3. Morphotectonic Stability of Rural settlements, based on Iat Index coefficients

\begin{tabular}{cccc}
\hline Zone & Number of Rural settlement & Percentage of settlements in each zone & Stability status \\
\hline A & 348 & 57 & Stable \\
B & 140 & 23.5 & More severe instability \\
C & 96 & 16 & moderate instability \\
D & 30 & 4.9 & Severe instability \\
Sum & 614 & 100 & \\
\hline
\end{tabular}

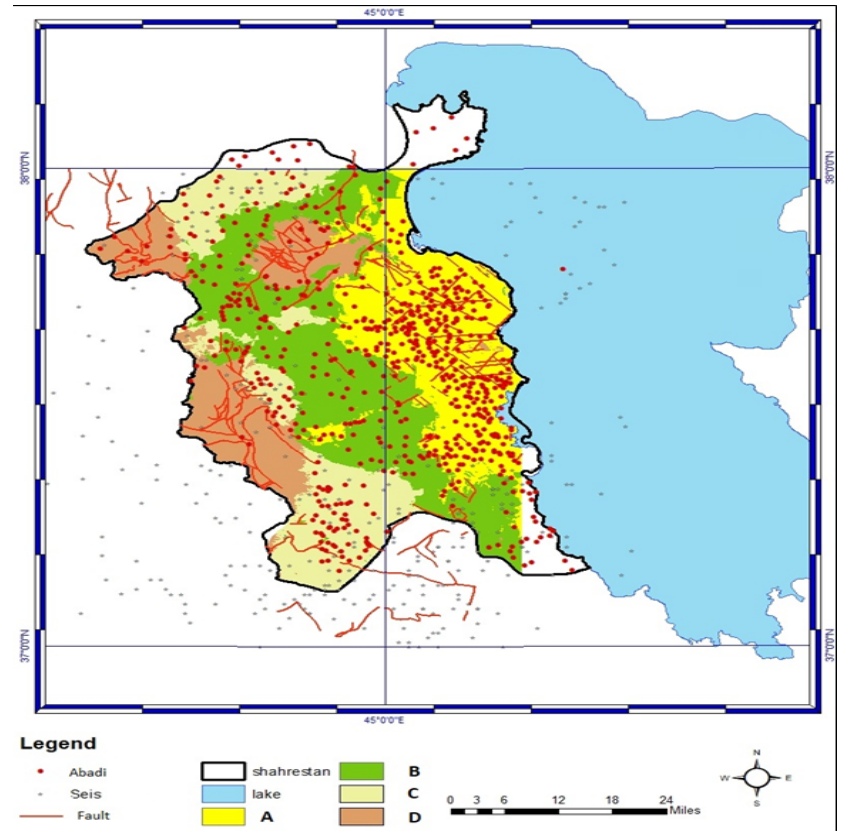

Figure 5. Morphotectonic zones, fuzzy spatial analysis and Isodata methods, region (author) 


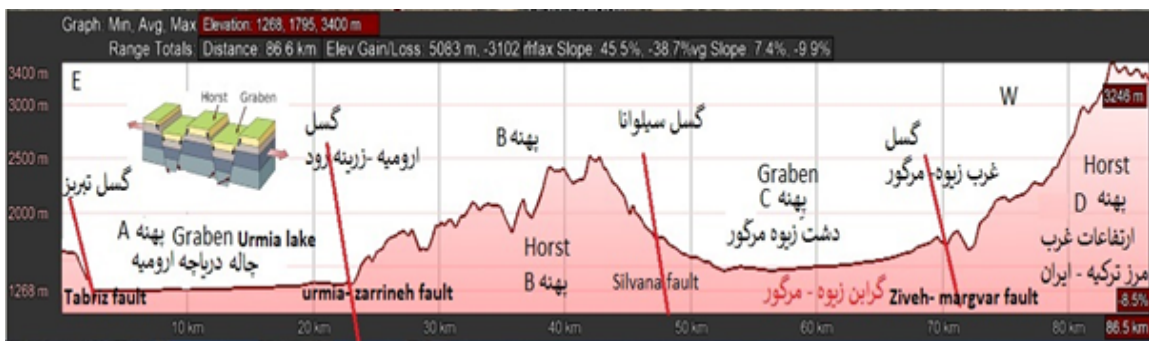

Figure 6. Landscape of morphotectonic zones of the western region of Lake Urmia, which is visible as fault moun- 0 JSRD tains

As mentioned earlier, this study is the first to address the issue of sustainability of rural settlements from a specialized perspective, namely morphotectonics. A review of research on the sustainability of rural settlements shows that few articles studied the sustainability of rural settlements from social (immigration), political, and managerial perspectives. Thus, it is clear that there is no comprehensive and systematic view on the sustainable development of rural settlements. The views are mostly political, social and managerial, wgich is not a good thing. For various reasons, rural centers are the most important economic, social and cultural units of the country and, along with cities, form the country's space organization. Their sustainable development plans require systematic and comprehensive studies.

\section{Conclusion}

In this study, the sustainability of rural settlements was considered with a new approach. It found that the nature of sustainability has a spatial origin. Spatial variables play an important role in the sustainability of the natural environment of rural settlements. Unlike urban settlements, rural settlements have a close and extensive relationship with the natural environment. Therefore, the effects of natural factors on their stability are more noticeable. Based on geomorphic indices, four morphotectonic units (A, B, C and D) were identified in the research area. Using the IAT index, the morphotectonic stability of the mentioned units was evaluated and determined. The results show that only zone A is stable and zone $\mathrm{B}$ shows very severe instability, $\mathrm{C}$ shows moderate instability and D shows severe instability.

The results show that rural settlements are classified into four categories based on morphotectonic stability. $57 \%$ of the settlements in the research area are in a stable condition. $23.5 \%$ are in more severe instability, $16 \%$ are in moderate instability and $9.4 \%$ are in severe instability. Prior to the investigation, their condition was unknown.
The results show that the effective factor in the morphotectonic instability of rural settlements is the activity of the fault system. This system is more active than other morphotectonic factors in the region and plays a decisive role in the sustainability of rural settlements.

Undoubtedly, other factors such as economic, social, political and managerial factors along with natural factors play a role in the sustainability of rural settlements. This issue deserves to be addressed with a systemic view.

\section{Acknowledgements}

This research did not receive any specific grant from funding agencies in the public, commercial, or not-forprofit sectors.

\section{Conflict of Interest}

The authors declared no conflicts of interest.

\section{References}

Aghanbati S. A. (2004). Geology of Iran. Iran Mines and Industries Organization Publications.

Ambersiz and Melville (1982) and Ambersiz (1988), Catalog of Iranian Earthquakes, download from the Internet.

Annabestani, A. A., \& Salehi, T. (1389). measuring the stability of habitats in alluvial fans Case study of Jovien plain, Quarterly Journal of Geography and Environmental Studies - First year No. 3 Spring 2010.

Arian, M., Bagha, N. (2012). Active Tectonics of Tehran Area, Iran, J. Basic. Appl. Sci. Res., 2(4)3805-3819, 2012.

B. F. J. Manley, translated by Dr. Mohammad Moghadam, Seyed Abolghasem Mohammadi Shouti and Mostafa Aghaei Sarbarzeh, Introduction to Multivariate Statistical Methods, Pishtaz Alam Publications, 1994. P. 208.

Bahrami, Sh. (2012). Morphotectonic evolution of triangular facets and wine-glass valleys in the Noakoh, anticline, Zagros, 
Iran: Implications for active tectonics, Elsevier journal homepage: www.elsevier.com/locate/geomorph Geomorphology $159-160$ (2012) 37-49.

Cotilla Rodríguez, M., CÓrdoba Barba, D. (2004). Morphotectonics of the Iberian Peninsula. Pure appl. geophys. 161, 755-815 (2004). https://doi.org/10.1007/s00024-003-2473-2

Darvishzadeh, A. (2006). Geology of Iran, Amir Kabir Publishing Institute 2006

Eyvazi Jedari, J. (2002). Geomorphology of Iran, Payame Noor University Press.

Eskandari Masoumeh et al. 2003, Earthquake risk zoning in Khuzestan province by probabilistic method, Internet.

Habibpour, K., \& Safari, R. (2009). Comprehensive guide to the use of SPSS in survey research (quantitative data analysis) Ghazal printing.

http:/ / www. Google Earth Images.

http://www.ngdir.ir: Geological Survey of Iran, major sedimentary-structural zones of Iran. National Earth Science Database.

Jafar Begloo, M., Moghimi, E., Yamani, M., Zamanzadeh, M., Kamrani Deli, H. (1398). Morphotectonic analysis of Karks mountain catchments on the Qom-Zafra fault system, Quantitative geomorphological research, 8th year, No. 1, Summer 1398 179-198

Karami, F. (2009). Geomorphic evaluation of tectonic activities in Saeed Abad Chay drainage basin - Natural Geography Research No. 69 Fall 2009, pp. 67-82.

Karimiparidari, S., Zaré, M., Memarian, H. (2011). New seismotectonic zoning map of Iran, 6th international conference Earthquake Engineering and Seismology, Tehran, Iran 2011.

Maghsoudi, M., Emami, K., Rasouli, A., Derakhshan, A., Jalali, Y., Moradipour, S., Moradipour, F. (1397). Estimation of tectonic activity in the southern part of Minab fault and its eastern fault system through morphometric data to determine the stability of the region (east of the Strait of Hormuz), Quantitative Geomorphological Research, Year 7, Issue 2, Fall, 1397, pp. 96-82.

Maghsoudi, M., Emami, K., Rasouli, A., Derakhshan, A., Jalali, Y., Moradipour, S., Moradipour, F. (1397). Estimation of the range of tectonic activity in the southern part of Minab fault and its eastern fault system through morphometric data to determine the stability of the region (East of the Strait of Hormuz), Quantitative Geomorphological Research, Year 7, Issue 2, Fall 2016, pp. 82-96.

Mahdavi, M., Ghadiri Masoom, M., \& Mohammadi Yeganeh, B. (2004). The role of natural geography factors in instability and rural migration in Zanjan province, Geographical Research, No. 48, summer 2004, pp. 205-222.

Manoj, J. M. (2016). Geomorphology and morphotectonic analysis of north Borneo, 2016.

Mirzaei, N. (2004). Tectonic states of Iran. Institute of Geophysics, University of Tehran, Educational Seminar, August 2004.

Mohammadi, N., Sadid Khoi, A., Sadoodi, F., \& Taghizadeh Farahmand, F. (1390). Moho depth changes in some tectonic zones of Iran using the receptor transfer function P method. Journal of Geophysics Volume 5, Number 4, pp. 132-152.

Moinfar, A.A., Naderzadeh, A., \& Nabavi, M.H. (2012). New Iranian Seismic Hazard Zoning Map for New Edition of Seismic Code and Its Comparison with Neighbor Countries, 15WCEE_1480, 2012.

Qalandarzadeh Abbas et al. (2003). Seismic microzonation of Urmia city using microthermal measurements, fourth International Conference on Seismology and Earthquake Engineering in Iran, Tehran and Iran.

Rabiee, M., Saghafi, M., Zanganeh Asadi, M. A., Ahmadi Abolghasem, A. (1399). Investigating the stability of the effect of proximity and interaction of geomorphic systems of water and wind formations of Petregan Playa, Geography and environmental stability, Volume 10, Number 34, pp. 1 to 20

Soleimani, M., Bouzarjomehri, Kh., Javan, J., Anabestani, A. A. (2015). Explaining the Factors Affecting the Instability of Rural Settlements in Iran, Journal of Rural Research and Planning, Volume 4, Number 3, Fall 2015, Serial Issue 11.

Yamani, M., Ghasemi, M. R., Alavi Panah, S. K., Gorabi, A. (2010). Morphotectonics of Dehshir region using geomorphometric techniques. Quarterly Journal of Natural Geography Research, Forty-second year, No. 71.

Zakerinejad, R., Hochschild, V., Rahimi, M., Maerker, M. (2016). Morphotectonic analysis of the Zagros Mountains Using High Resolution DEM to Assess Gully Erosion Processes: A Case Study in the Fars Province, Southwest of Iran, IGRDJ Journal Vol. 6, Issue 4, March 2016.

Zamani, A., Nedaei, M., \& Boostani, R. (2009). Tectonic Zoning of Iran Based on Self-Organizing Map. Journal of Applied Sciences, 9: 4099-4114. 
